\title{
Uma defesa
} apaixonada do modernismo

\author{
Paulo Bruna
}

Em seu último número como editor da revista italiana Casabella, Tomás Maldonado organizou uma intransigente defesa do Movimento Moderno sob o indicativo título: "Il Movimento Moderno e la questione 'post' ". $\mathrm{Na}$ introdução escreveu: (...) “'se quisermos abrir a discussão de forma rigorosa, devemos necessariamente afrontar o tema da modernidade em todas as suas implicações, tamberm naquelas, e sobretudo naquelas, que concernem à modernidade como projeto de desenvolvimento das forças produtivas, como projeto decididamente inovador da ordem social e cultural'(1). Após analisar as várias implicações de uma possível sociedade pós-industrial e pós-moderna Maldonado coloca, sem no entanto respondê-la, uma questão realmente importante: (...) "se o pósmodernismo se propõe a negar ou superar o modernismo, parece-me no mínimo oportuno saber antes de mais nada quais são as categorias culturais e projetuais que a noção de modernismo efetivamente cobre (...)"(2). Pois bem, nestes últimos anos, à margem de uma verdadeira enxurrada de publicações superficiais e oportunistas, foram surgindo algumas respostas a essa questão de forma objetiva e construtiva. O próprio Tomás Maldonado publicou na Itália, ainda sem tradução brasileira, Il Futuro della Moderni$t \grave{a}^{(3)}$ no qual, através de uma densa linguagem filosófica, procura entender quais os possíveis caminhos que a arquitetura, o planejamento urbano e territorial e o desenho industrial poderão trilhar no futuro. David Harvey faz um amplo levantamento do que entende ser The Condition of Postmodernity(4) que tem como subtítulo: "An Enquiry into the Origin of Cultural Change''(5). Mas foi Anatole Kopp, através deste livro absorvente e fascinante, que felizmente acaba de chegar às livrarias brasileiras em impecável tradução de Edi G. de Oliveira e revisão/coordenação da arquiteta e editora Carla Milano Benclowicz, quem melhor entendeu e esclareceu a quais categorias culturais e projetuais a noção de modernismo efetivamente responde.

Para Kopp a ideologia "moderna" na arquitetura e no urbanismo deverá surgir dos escombros da Primeira Guerra Mundial, ainda que tenha raízes mais profundas nos movimentos operários do século XIX e nas utopias que, como as de "Fourier ou de Tchernychevski descreviam não só a sociedade ideal do futuro, mas tambêm seu meio ambiente construído (...)" (p. 16). Assim, será a construção dos grandes conjuntos habitacionais siedlungen-alemães e hofs-austríacos, que concretamente realizarão pela primeira vez essa arquitetura de "massa", agrupando ao redor de infra-estruturas sociais, culturais e técnicas, centenas e às vezes milhares de habitações populares. Essas realizaçōes, independentemente da linguagem formal com que se apresentavam, tinham uma série de pontos em comum, de maneira que se poderia dizer que constituíram uma nova tipologia. Os elementos constantes dessa nova tipologia eram, em síntese, os seguintes:

- O projeto da habitação resultava de um complexo estudo racional e científico, que visava dar a todos os moradores os mesmos direitos, "mas essa igualdade de direitos não define os próprios direitos. O que se pode e o que se deve dar a cada um em matéria de habitação, levando-se em conta as condições econômicas e financeiras do mo-

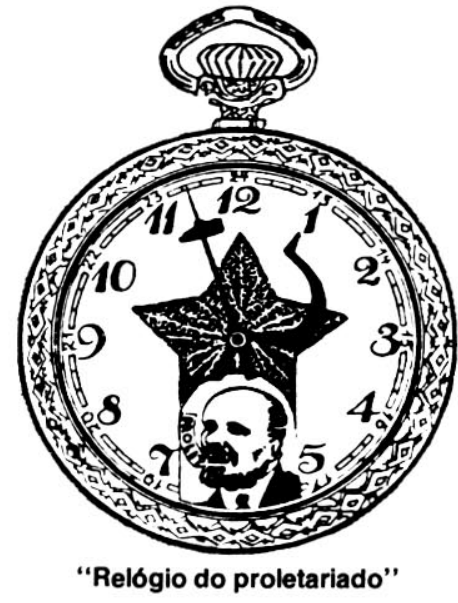

PAULO BRUNA é arquiteto $e$ professor de História da Arquitetura Contemporânea na FAU-USP.

Quando o moderno năo era um estilo e sim uma causa, Anatole Kopp. Săo Paulo, Nobel/Edusp, 253 pp.

1 "II Movimento Moderno e la questione "post'" ", Tomás Maldonado, in Casabella $n^{2} 463 / 464$, Milano, nov.dez./1980.

2 Idem, p. 13.

3 II Futuro della Modernità, idem. Milano, Feltrinelli Editore, 1987.

4 The Condition of Postmodernity, David Harvey. Oxford, Basil, Blackwell, 1989.

5 Nessa linha de pesquisa foram publicados recentemente alguns livros extremamente interessantes, como por exemplo: Modernismo - guia geral 1890-1930, Malcolm Bradbury e James Mc Farlane (org.). Traduçăo de Denise Bottmann. Sáo Paulo Com Denise Boltmann. Sao Paulo, Com-

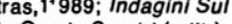
Moderno, Maria Grazia Sandri (edit.). Milano, CLUP Cooperativa Libraria Universitária del Politécnico, 1987; Architecture, criticism, ideology, Joan Ockman (edit.). Princeton, NJ, Princeton Architectural Press, 1985.

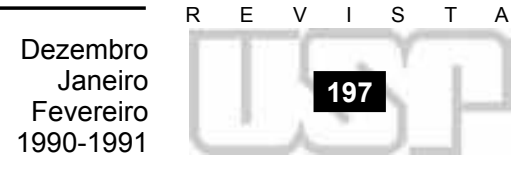


Abaixo, o Siedlung Britz em Berlim, projetado por Bruno Taut; na outra página, acima, capa da revista Levyi Front iskustv de março de 1923 e que tinha como redator-chefe o poeta russo Vladimir Maiakóvski; abaixo, o Carl Mackley Housing em Filadélifia (EUA), projetado por Oscar Stonorov e Alfred Kastner (1933-35) mento? Quais as necessidades que devem ser satisfeitas quanto à superfície habitável, aparelhos diversos e equipamentos? Esse é o problema central ao qual se atêm os arquitetos do 'Neues Bauen' em sua prática profissional e enquanto problema teórico. Trata-se de definir com precisão o que será chamado de die Wohnung für das Existensminimum. Essa noção de minimum não está ligada exclusivamente a questōes financeiras e econômicas (...)" (p. 51).

- O próprio conceito da habitação mínima deve ser equacionado adequadamente, induzindo o morador a tornar-se racional. (...) "para essa racionalização três condiçōes são essenciais (...) viver de outra maneira, ou seja, que cada habitante tenha seu próprio quarto, 'não importa quão pequeno', dirá Gropius; que a cozinha seja concebida de maneira a simplificar ao máximo o trabalho doméstico e que a mobnlia, enfim, não imite o mobiliário burguês, mas seja, ao contrário, concebida em função de uma manutenção simples, de condições de vida higiênicas e de um preço baixo (...)" (p. 53).

- A noção de que a habitação mínima deve ser o meio para passar a uma outra maneira de viver, ser o instrumento de uma Neue Wohkultur (uma nova cultura da habitação), induzindo a mudanças no modo de vida e conseqüentemente no comportamento social. (...) "a idéia dominante, como no que se refere à própria habitação, é que tudo o que constitui o ambiente material da vida cotidiana influi sobre o comportamento e participa assim da transformação progressiva da natureza humana. Os grandes equipamentos coletivos do bairro, as lavanderias coletivas, as creches, as salas de reunião têm a mesma função. Sua multiplicação contribui, ao transferir para fora da habitação familiar tarefas domésticas que antes ali ocorriam, para a evolução do conceito mesmo de família e para acelerar a passagem da famńlia extensa, necessária para a realização dessas tarefas dentro de casa, para a família 'moderna', reduzida aos pais e aos filhos e que se apoia, para a maior parte de suas atividades, em uma rede de equipamentos, que permite a socialização dessas atividades (...)"' (p. 60).

- A construção em massa de habitações mínimas tinha como pressuposto a industrialização dos componentes da construção; sua produção em série em usinas e sua montagem na obra. (...)“a produção artesanal deve ceder seu lugar à produção industrial na

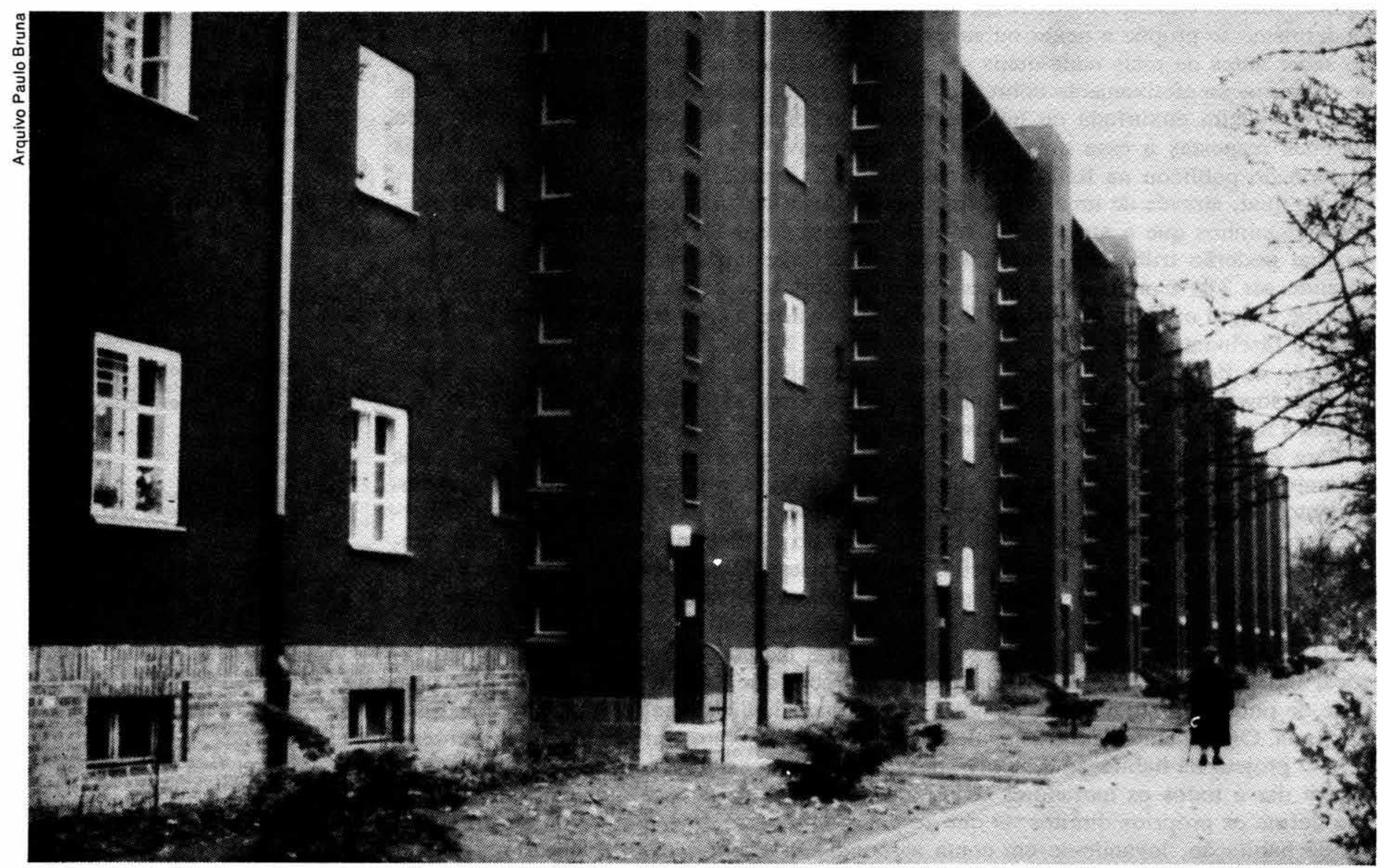

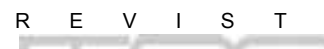

Dezembro

Janeiro

Fevereiro 1990-1991 
construção; a idéia de série e de industrialização é central na nova arquitetura dessa época. Fabricar habitaçōes como se fabricam automóveis permitirá, acredita-se, diminuir o preço, como aconteceu com o automóvel. Daí a idéia da 'máquina de morar' - expressão de Le Corbusier - mas conceito comum a todos os arquitetos da nova arquitetura (...)" (p. 50).

- A organização urbanística racional dessas habitações, conferindo a todas, indistintamente, as mesmas condições de insolação, ventilação e acesso ao verde. (...) “tão tragicamente ausentes das habitações operárias da Grande Berlim, dessa Berlim de pedras, a 'Steineres Berlim', que Werner Hegeman descreveu como a maior Mietskasernestadt do mundo, com seus pátios interiores sucessivos de cinco metros de largura por seis andares de altura, seus quartos enterrados no subsolo e sua média de 4,5 habitantes por cômodo"'(...) (p. 19).

- Finalmente, a noção de que somente o Estado, através de sua autoridade, seria ca-
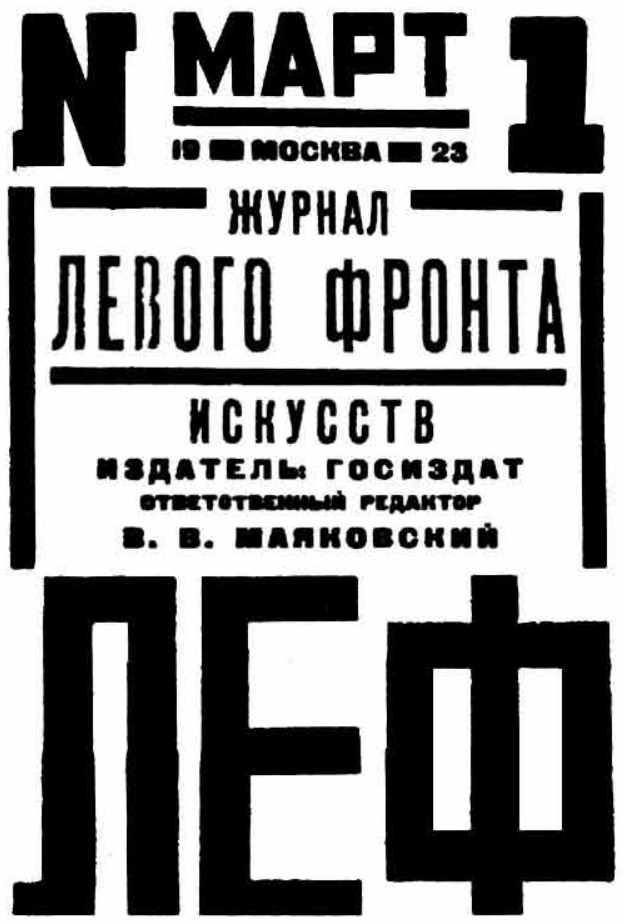
paz de superar os problemas da posse privada da terra urbana e de realizar os vastos programas que a sociedade industrial requeria. Foram as administrações sociais-democratas que edificaram a maior parte dos conjuntos modernos entre 1925 e 1933 em Berlim, Dessau, Frankfurt, Hamburgo, Magdeburgo e vários outros lugares, e seus arquitetos foram Bruno Taut, Martin Wagner,
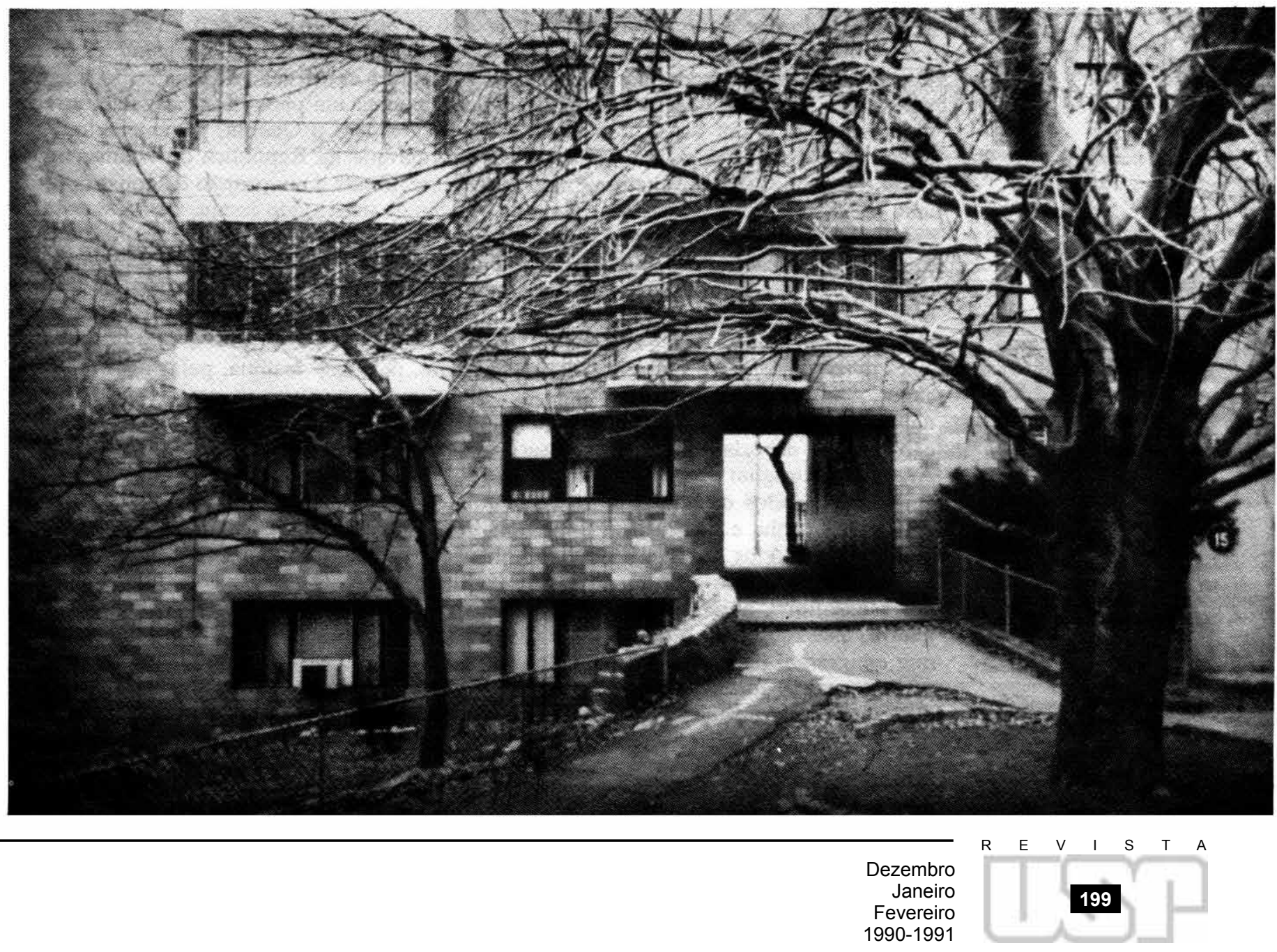
6 L'Architecture de La Reconstruction 1945-1955, Anatole Kopp. Frédérique Boucher e France Danièle. Paris, Ed. du Moniteur, 1983.

7 VIIle et Révolution. Architecture et Urbanisme Soviétiques des années Urbanismo Soviotiquos dos anné vingt, An pos, 1967; Architecture et Mode de Vie. Textes des années 20 en URSS. idem. Grenoble, Presses Universitaires de Grenoble, 1979; Constructivist Architecture in the USSR, idem. London. Academy Editions, 1985.

8 L'Architecture de la Période Stalinienne, Anatole Kopp. Grenoble, PUG - Ecole Nationale Superieure des Beaux-Arts, 1985.

9 Building New Communities: New Deal America and Fascist Italy, Dianne Amorica and Fascist Italy, Dianne 1989; Building Mo dern Italy: Italian Architecture 1914-1936, Dennis Doordan, New York, Princeton Architectural Press, 1989 .
Walter Gropius, Mart Stam, Otto Hasler, Fred Forbat, Ernst May, Hans Scharoun, etc.

São essas noções que estão para Kopp na origem daquilo que se convencionou chamar de movimento moderno, não como mais um estilo a disputar a preferência dos arquitetos, mas como uma causa moral, enraizada em convicções de progresso social, material e político.

Este livro, editado na França em 1988, foi o último trabalho publicado do autor, falecido em maio deste ano em Paris. Nascido na Rússia, educado na Alemanha, estudou arquitetura na Ecole Speciale d'Architecture de Paris e em seguida no Massachusetts Institute of Technology onde diplomou-se. Essa formação, que lhe dava a familiaridade, o domínio da língua e da cultura desses países, explica em boa parte a originalidade de suas pesquisas, todas centradas nos anos 20 e 30, a cavaleiro entre as duas guerras mundiais. Ainda que tenha escrito um balanço crítico da reconstrução na França no período $1945-55^{(6)}$, sua importância reside na pesquisa de documentos originais na Alemanha e na União Soviética ${ }^{(7)}$ a partir dos quais reconstruiu de forma precisa, minuciosa e atenta o desenvolvimento da arquitetura e do urbanismo "modernos". É precisamente este o itinerário do livro, que a partir da República de Weimar - “em direção ao sol, em direção à liberdade" - descreve a reconstrução do modo de vida na URSS dos anos 30 e o panorama da França, onde havia apenas - "Le Corbusier e dois ou três outros". O panorama amplia-se para incluir a política do New Deal nos EUA e a difusão desses ideais a terras distantes levados pelos arquitetos que emigram em números muito significativos seja da Alemanha nazista, seja da URSS, a partir de 1932, quando torna-se política oficial o realismo socialista ${ }^{(8)}$. É particularmente interessante acompanhar a trajetória individual desses arquitetos para os Estados Unidos e para a Palestina. Nos EUA os arquitetos europeus exercerão uma considerável influência, sobretudo Mies van der Rohe nos anos posteriores à Segunda Guerra. Mas trata-se, segundo Kopp, “de um período posterior ao do nascimento da arquitetura 'moderna' e durante o qual a 'causa' defendida pelos arquitetos da Bauhaus ou por aqueles que eles formaram será uma causa técnica, formal e - é preciso dizê-lo - comercial, ou seja, completamente diferente da 'causa' social dos arquitetos 'modernos' europeus dos anos 20" (p. 232).

Parece bastante diferente o desenvolvimento da arquitetura "moderna" nos países do Terceiro Mundo. Para muitos arquitetos desse período fica claro que somente os países jovens em formação poderiam ter as condições para a construção de uma sociedade nova e aberta, na qual a arquitetura poderia desempenhar um papel modernizante, ativo e vigoroso. Não é por acaso que Ernst May emigra para o Quênia, por exemplo. Para Kopp, na Palestina dos anos 30, da mesma forma que na República de Weimar ou na URSS dos anos 20, a arquitetura "moderna" corresponde a um projeto de construção de uma sociedade nova, baseada na idéia de criação de um Estado Judeu. Os kibbutz são a expressão mais completa dos objetivos essenciais do movimento socialista sionista, isto é, acabar de uma vez por todas com o gueto, reinserindo o povo judeu no trabalho agrícola, pois, a exemplo dos populistas russos, acreditavam que o camponês deveria ser a base da nova sociedade e a classe operária, a exemplo de todos os marxistas, devia ser o motor da história.

O livro é fascinante também pelo que não diz, pelo que insinua, pelas aberturas que sugere, pelas pesquisas que motiva. Fica claro que as histórias da arquitetura tradicionais não conseguem acompanhar aquilo que Kopp chama de "arquitetura da emigração", e que deveriam incluir, necessariamente, os países da América Latina, o Chile, Argentina, Uruguai e o Brasil em particular. Esses países receberam grandes levas de emigrantes vindos da Hungria, da Polônia, da Tchecoslováquia, mas sobretudo da Itália, da Alemanha e da Áustria. Entre eles havia numerosos técnicos, engenheiros e arquitetos partidários do "Neues Bauen" alemão. Trabalhos extremamente recentes, comparando o urbanismo do New Deal rooseveltiano às novas cidades construídas na Itália por Mussolini ${ }^{(9)}$, abrem perspectivas para explicar não só a arquitetura italiana do pósguerra, mas sobretudo a formação, a experiência e a perspectiva dos arquitetos italianos que emigraram para o Brasil naqueles anos. Percebe-se assim como uma nova rede de relações vai-se formando, com novas aberturas explicativas, sugerindo que o trabalho de interpretação apenas começou. Um livro é seminal não apenas pelo que relata, mas também pelo que sugere e motiva, como é o caso deste magnífico trabalho do professor Anatole Kopp.

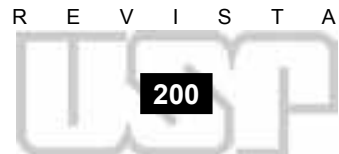

Dezembro

Janeiro

Fevereiro

1990-1991 